\title{
DETERMINATION OF HUMIDITY LEVEL IN AERATED CONCRETE CONSTRUCTIONS BY NON DESTRUCTIVE TESTING METHODS
}

\author{
Sanita Rubene ${ }^{1}$, Juris Noviks ${ }^{2}$, Martins Vilnitis ${ }^{3}$ \\ ${ }^{1,2,3}$ Department of Construction Technology, Faculty of Civil Engineering, Riga Technical University, 16/20 Azenes Str., \\ LV-1048, Riga, Latvia \\ E-mail: ${ }^{1}$ sanita.rubene@inbox.lv(correspondingauthor); ${ }^{3}$ martins.vilnitis@rtu.lv
}

\begin{abstract}
In the time of energy saving it is important to save heating costs. Different methods of thermo insulation are developed and one of them, besides the comprehensive use of thermo insulation materials, is the use of masonry consisting of aerated concrete blocks. In order to determine the contribution of aerated concrete to the total scope of heat insulation it is important to determine the distribution of humidity in the wall construction. As the construction terms are short and usually all tests are done in the habitable buildings, it is difficult to use destructive methods for the determination of humidity level in the wall constructions. This is the reason why the importance and frequency of application of non destructive methods for detection of wall humidity are increasing. One of such methods for non destructive determination of humidity level in aerated concrete constructions is application of electrical impedance spectrometry. In laboratorial test series it is detected that along with the increasing of the humidity level in aerated concrete block the electrical impedance of the construction decreases. Using this method it is possible to detect the distribution of humidity throughout the construction in relative means. If absolute means are important, then calibration work must be performed prior to field testing. In order to increase the accuracy of the results obtained, the frequency analysis must be performed for every type of testing material. In this paper non destructive testing of aerated concrete blocks for determination of the distribution of humidity level as well as frequency analysis for aerated concrete blocks is described.
\end{abstract}

Keywords: aerated concrete, non destructive testing, electrical impedance spectrometry, determination of humidity distribution.

\section{Introduction}

In the time of energy saving it is important to save heating costs. Different methods of thermo insulation are developed and one of them, besides the comprehensive use of thermo insulation materials, is the use of masonry consisting of aerated concrete blocks. In order to determine the contribution of aerated concrete to the total scope of heat insulation it is important to determine the distribution of humidity in the wall construction [6]. As the construction terms are short and usually all tests are done in the habitable buildings; it is difficult to use destructive methods for the determination of humidity level in the wall constructions. This is the reason why the importance and frequency of application of non destructive methods for detection of wall humidity are increasing [1, 10]. One of such methods for non destructive determination of humidity level in aerated concrete constructions is application of electrical impedance spectrometry. In laboratorial test series it is detected that along with the increasing of the humidity level in aerated concrete block the electrical impedance of the construction decreases [9, 15, 16]. Using this method it is possible to detect the distribution of humidity throughout the construction in relative means. If absolute means are important, then calibration work must be performed prior to field testing. In order to increase the accuracy of the results obtained, the frequency analysis must be performed for every type of testing material. In this paper non destructive testing of aerated concrete blocks for determination of the distribution of humidity level as well as frequency analysis for aerated concrete blocks is described. The possibility of application EIS for determination of the humidity distribution throughout the aerated concrete block in relative means is set as the main aim of this research. In order to reach the aim three sets of experiments will be performed. Each experiment carries different meaning. The experiment No. 1 will be carried out to perform frequency analysis for the material and obtain the best frequency for further testing, experiment No. 2 will be performed using semi destructive testing method of EIS for detection of the humidity distribution throughout the aerated concrete block and experiment No. 3 will be performed using non destructive testing method for determination of the humidity distribution throughout the aerated concrete block.

\section{Method of electrical impedance spectrometry (EIS)}

Method of electrical impedance spectrometry (EIS) enables detection of the distribution of impedance or other electrical variables (such as resistivity, conductivity etc.) inside a monitored object, and thus the observation of its inner structure and its changes [11, 13]. This method is ranked among indirect electrical methods and it is used in measuring properties of organic and inorganic substances. It constitutes a very sensitive tool for monitoring phenomena that take place in objects (e.g. changes occurring in earth filled dams when loaded by water, in wet masonry sediments etc.), electrokinetic phenomena at boundaries (e.g. electrode/soil grain, between soil grains) or for describing basic ideas about the structure of an inter phase boundary (e.g. electrode/water) [14].

The EIS is based on the periodic driving signal the alternating signal. If low amplitude of the alternating signal is used, concentration changes of charge are 
minimal at the surface of an electrode connected with the measured surface, which is very important in the systems sensitive to so called concentration polarization. The range of frequencies used for the driving signal enables the characterisation of systems comprising more interconnected processes with different kinetics.

In the Laboratory of Water - Management Research of the Institute of Water Structures at the Faculty of Civil Engineering of Brno University of Technology, a measuring instrument with a Z-meter III device has been developed within the solution of an international project E!4981 of programme EUREKA. This instrument is verified in laboratory experiments and measurements on objects in situ. [1]

So far, research work of humidity distribution and level determination with the Z-meter III device has been done for soil, concrete constructions and brick (stone as well as ceramics) cladding. These researches prove that EIS can be applied for determination of humidity level in solid building constructions. Such researches were performed by the scientist of the Brno University of technology Jana Parilkova [2.,3.,5.].

In this paper laboratory research results for aerated concrete blocks are presented.

In further experiments the Z-meter III device will be used for determination of the humidity distribution in aerated concrete blocks. [4.]

\section{Monitoring of changes in humidity distribution of aerated concrete blocks by EIS}

Experiment $\mathrm{N}^{\mathbf{0}} 1$. Frequency analysis for the detection of humidity distribution throughout an aerated concrete blocks by application of EIS

Experiment $\mathrm{N}^{\circ} 1$ was performed on aerated concrete block with dimensions $600 \times 375 \times 200 \mathrm{~mm}$ [7.]. Such blocks are commonly used for wall constructions in residential and office buildings. In the particular experiment two holes with depth of $300 \mathrm{~mm}$ were drilled in the aerated concrete block. The distance between holes was $250 \mathrm{~mm}$. This block was used to carry out frequency analysis for the detection of humidity distribution throughout the block.

For this experiment Z-meter III device with two probes ( 6 active transmitter and receiver channels each) will be used.

The frequency analysis was done in three steps - for air dry block, for block where $150 \mathrm{ml}$ of water was poured on the top of the block prior to the inserting of probes in the holes, in such a way different humidity level throughout the height of block was obtained and last for the block where additional $150 \mathrm{ml}(300 \mathrm{ml}$ in total $)$ of water were poured on the top of the block.

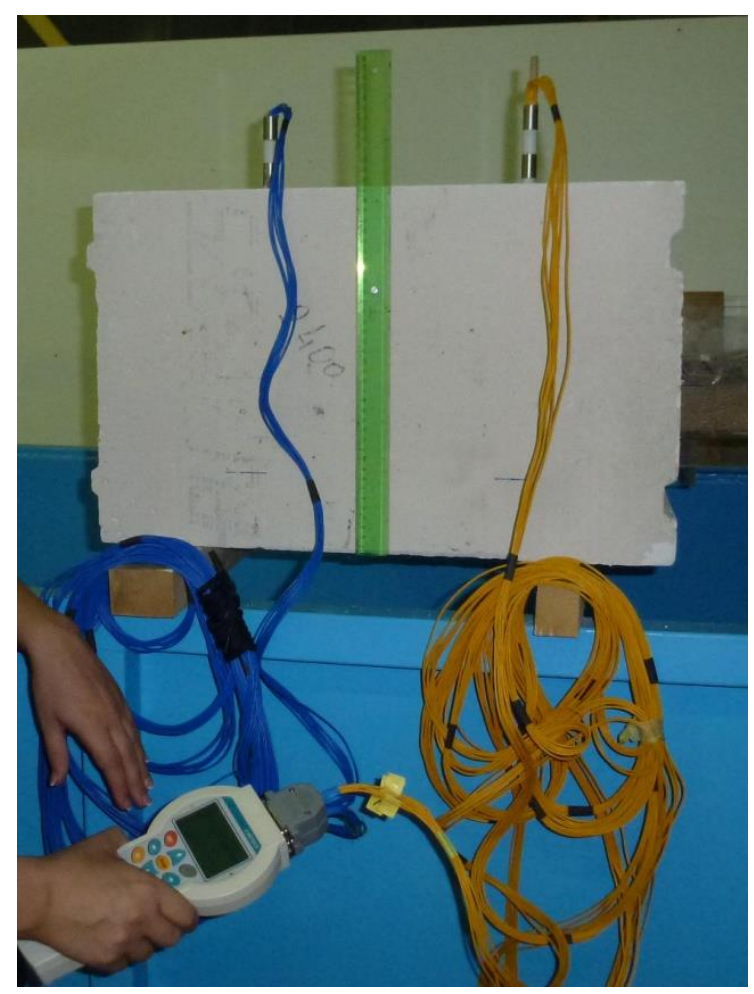

Fig. 1. Experimental aerated concrete block with probes and Z-meter III.

Frequency analysis was done for the following frequencies and frequency steps as described in Table 1.

Table 1. Frequency analysis for aerated concrete block using EIS

\begin{tabular}{|c|c|c|c|}
\hline $\begin{array}{c}\text { Number of probe } \\
\text { channels used }\end{array}$ & $\begin{array}{c}\text { Beginning } \\
\text { frequency, } \\
\mathrm{Hz}\end{array}$ & $\begin{array}{c}\text { End } \\
\text { frequency, } \mathrm{Hz}\end{array}$ & $\begin{array}{c}\text { Measur- } \\
\text { ement step, } \\
\mathrm{Hz}\end{array}$ \\
\hline 6 & 1000 & 91000 & 10000 \\
6 & 1000 & 100000 & 500 \\
6 & 1000 & 100000 & 1000 \\
\hline
\end{tabular}

In such a way three sets of the results containing three sets of data for different humidity level of the block (airdry; $150 \mathrm{ml}$ of water in block and $300 \mathrm{ml}$ of water in block) were obtained.

From the results of all three sets of experiments it is visible that with low frequency of testing such as 1,000 to $2,000 \mathrm{~Hz}$ and with high frequencies of testing such as 15,000 to $100,000 \mathrm{~Hz}$ the differences between measurements in one frequency are very small, so these frequencies cannot be used for precise determination of humidity changes in the aerated concrete block.

An example of the frequency analysis for aerated concrete block testing is shown in Table 2 . 
Table 2. Frequency analysis for aerated concrete block using EIS in different frequencies and with different humidity level (part of results)

\begin{tabular}{|c|c|c|c|c|}
\hline No & $\mathrm{f}[\mathrm{Hz}]$ & channel & $\mathrm{Rx}[\mathrm{ohm}]$ & $\mathrm{Xx}[\mathrm{ohm}]$ \\
\hline 1 & 1000 & 0 & 101.7 & -51.4 \\
\hline 1 & 1000 & 0 & 101.4 & -51.3 \\
\hline 1 & 1000 & 0 & 101.5 & -51.3 \\
\hline 37 & 4000 & 0 & 207296.3 & -476674.7 \\
\hline 37 & 4000 & 0 & 137043.4 & -85722.5 \\
\hline 37 & 4000 & 0 & 114436.3 & -66200.8 \\
\hline 73 & 7000 & 0 & 136055.5 & -317477.1 \\
\hline 73 & 7000 & 0 & 103593.0 & -76493.6 \\
\hline 73 & 7000 & 0 & 90706.8 & -60517.8 \\
\hline 85 & 8000 & 0 & 127428.2 & -291381.0 \\
\hline 85 & 8000 & 0 & 95602.4 & -73590.1 \\
\hline 85 & 8000 & 0 & 84870.7 & -58771.5 \\
\hline 97 & 9000 & 0 & 110885.8 & -260369.7 \\
\hline 97 & 9000 & 0 & 89585.8 & -71004.3 \\
\hline 97 & 9000 & 0 & 78670.7 & -58485.2 \\
\hline 109 & 10000 & 0 & 104381.5 & -241235.0 \\
\hline 109 & 10000 & 0 & 84838.5 & -68524.9 \\
\hline 109 & 10000 & 0 & 71266.9 & -57383.5 \\
\hline 169 & 15000 & 0 & 76834.8 & -176502.9 \\
\hline 169 & 15000 & 0 & 66214.5 & -60529.8 \\
\hline 169 & 15000 & 0 & 60755.2 & -50297.8 \\
\hline 229 & 20000 & 0 & 52957.3 & -127714.3 \\
\hline 229 & 20000 & 0 & 53429.2 & -52648.0 \\
\hline 229 & 20000 & 0 & 45965.3 & -44314.3 \\
\hline
\end{tabular}

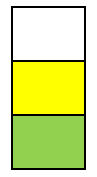

air dry sample

sample containing $150 \mathrm{ml}$ of water

sample containing $300 \mathrm{ml}$ of water

$\mathrm{f}$ - frequency of measurement, $\mathrm{Hz}$;

channel - the code No of the transmitter channel;

$\mathrm{Rx}$ - real part of electrical impedance for each measurement, ohm;

$\mathrm{Xx}$ - imaginary part of electrical impedance for each measurement, ohm.

The experiment shows that the widest diversity of the obtained data is at frequencies from 4,000 to $15,000 \mathrm{~Hz}$.

$8,000 \mathrm{~Hz}$ was chosen as the most appropriate frequency for further testing as it is the mean value from the range obtained in the experiment.
Experiment $N^{\circ}$. Detection of humidity distribution throughout an aerated concrete block by two probes and application of EIS

Experiment $\mathrm{N}^{\circ} 2$ was performed on aerated concrete block with dimensions $600 \times 375 \times 200 \mathrm{~mm}$. In this experiment the same block as in experiment $\mathrm{N}^{\circ} 1$ is used. In this experiment two probes with 6 channels in each probe were used. The electrical impedance was measured as shown in Fig 2.

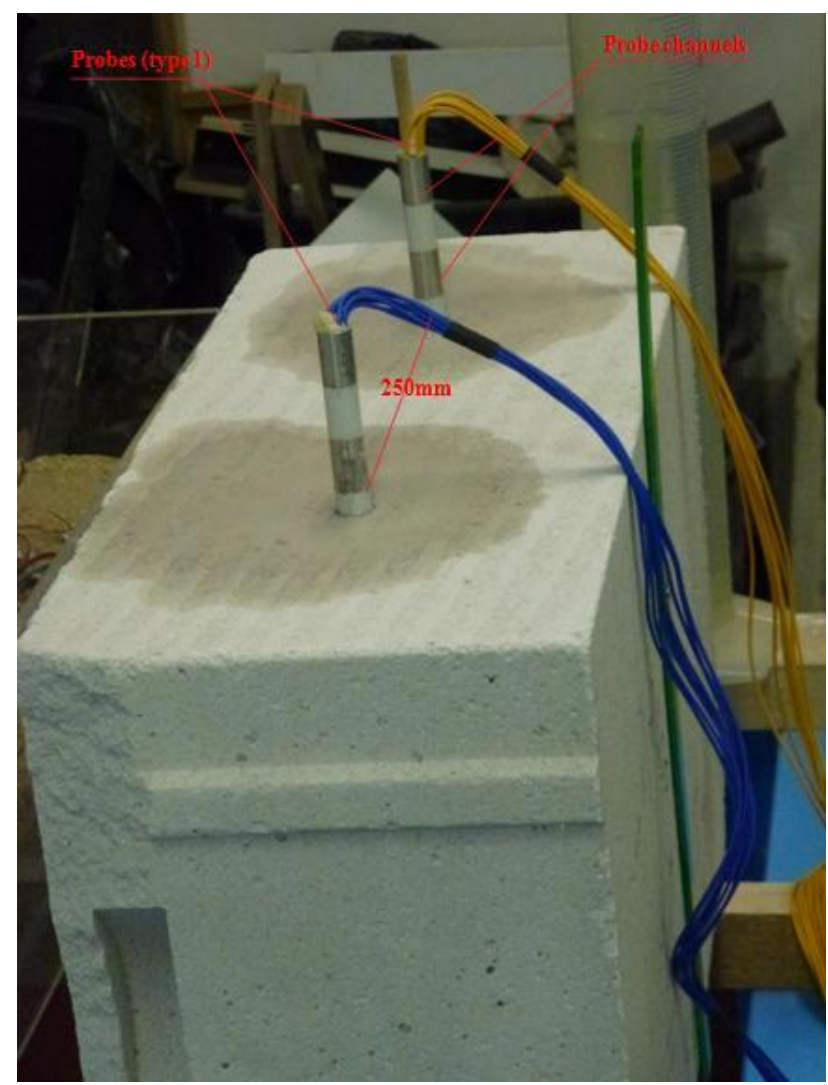

Fig. 2. Scheme of probe and channel placement.

The experiment was done in the following steps: EIS test was applied on air dry aerated concrete block, and then the block was exposed to the impact of water. Water was poured on the top of the aerated concrete block in order to obtain different humidity distribution throughout the height of the block. Each time the block was exposed to the impact of water, the EIS measurements by Z-meter III were taken.

The experiment was performed with the changing number of probes. For the air dry block all six channels of each probe were used for the determination of electrical impedance of the block in different layers; for the block after average exposition to water impact one channel of the probe was used considering that water cannot immediately penetrate into all block height; and after long exposition to the impact of water 2 and 3 channels of each probe were used.

In this experiment the changes of relative humidity throughout the block were measured, so the calibration work was not performed. 
In Fig. 3 the graphical result of the testing is shown.

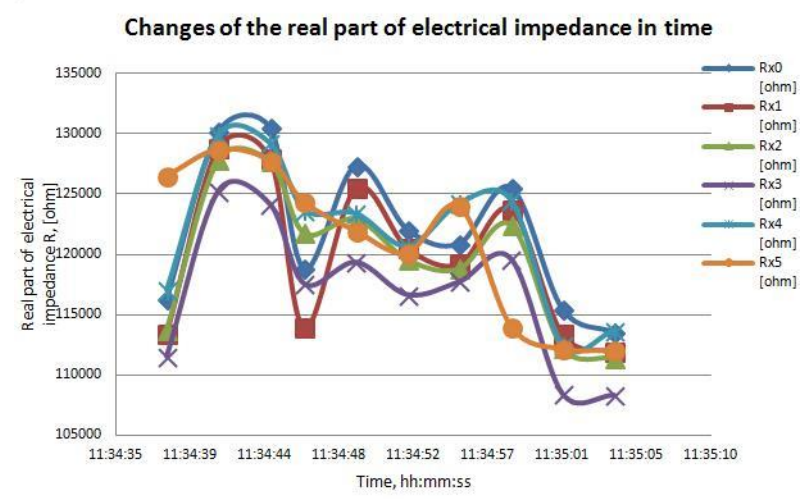

Fig. 3. Changes of the real part of electrical impedance depending on the depth of probe and time.

$\mathrm{Rx} 0 . . .5$ - Real part of the electrical impedance for each channel of probes. 0 refers to the bottom channel and 5 refer to the upper channel.

As it is reflected in Fig. 3, the real part of electrical impedance in air dry aerated concrete block is similar throughout all block height. The measurement $\mathrm{N}^{\circ} \mathrm{Rx} 5$ should not be taken into consideration due to the fact that it is the upper channel of the probe and the impact of air is not excluded in this measurement. All other graphs have the same character so it is possible to state that the distribution of humidity in the block is even and there are no significant differences.

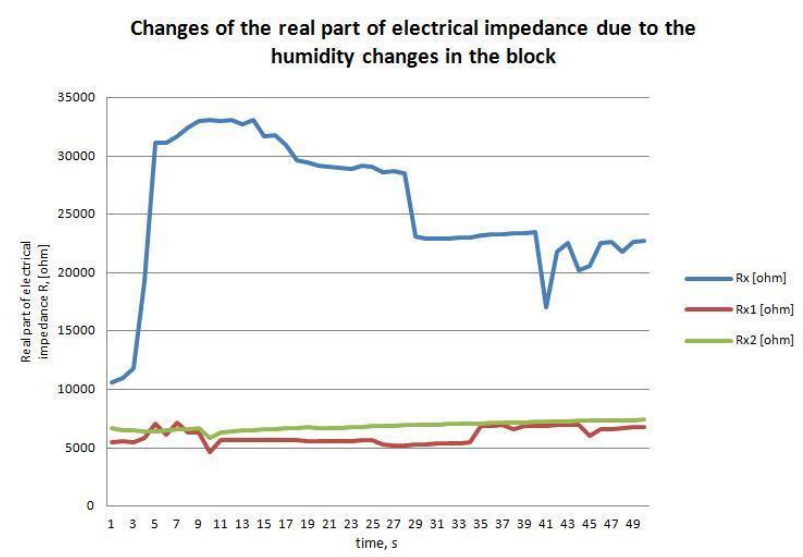

Fig. 4. Changes of the real part of electrical impedance due to the humidity changes in the aerated concrete block.

In Fig. 4 the difference of the real part of electrical impedance for aerated concrete block with different level of humidity is shown. According to the experiment results $\mathrm{Rx}$ chart shows the dynamics of electrical impedance for an air dry block, the Rx1 chart shows the results for wet aerated concrete block $(150 \mathrm{ml}$ of water were poured on the same block and measurements were taken as previously stated) and the Rx2 chart shows the results for the same block and same place after 30 minutes of drying time.

It is clear that the difference in electrical impedance for air dry and humid block varies in the range of 500\%, so the results of humidity level changes are obvious. The Rx 2 chart also shows that after short drying time of $30 \mathrm{~min}$ at room temperature (about $+25^{\circ} \mathrm{C}$ ) the electrical impedance grows by about $2-5 \%$, what confirms the statement that the dryer the construction is the higher is the electrical impedance. In this case capillarity is important as well as the drying process due to the structure properties of aerated concrete [10.,12.].

This experiment shows that electrical impedance spectrometry can be used for relative determination of the humidity level in aerated concrete blocks as a non destructive method, bearing in mind that the probes should be inserted in the construction and sealed to avoid the impact of the surrounding environment to the test results.

The weight of the block before and after the impact of water is not significant in this experiment as the aim of the experiment was to determine the relative difference of the humidity in the block. If an aim is set to determine average absolute humidity level in the block or distribution of the humidity in absolute means throughout the block, prior calibration of the device is mandatory, which includes determination of the humidity level by water saturation and weighting of the aerated concrete samples.

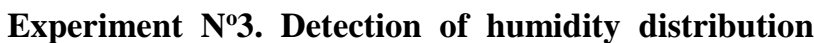 throughout an aerated concrete block by separate and application of EIS}

In experiment $\mathrm{N}^{\circ} 3$ humidity distribution in the aerated concrete block was also measured with Z-meter III, but in this case different type of probes was used. These probes allow completing fully non destructive test as they are connected to the surface of the block and no drilling is necessary for inserting of type 1 probes, which were used for the first two experiments.

In this case 14 pairs of sensors were attached to the experimental block. At first the humidity distribution was measured in the air dry block, and then gradually the humidity level in the block was increased by pouring water on the top of the block. 


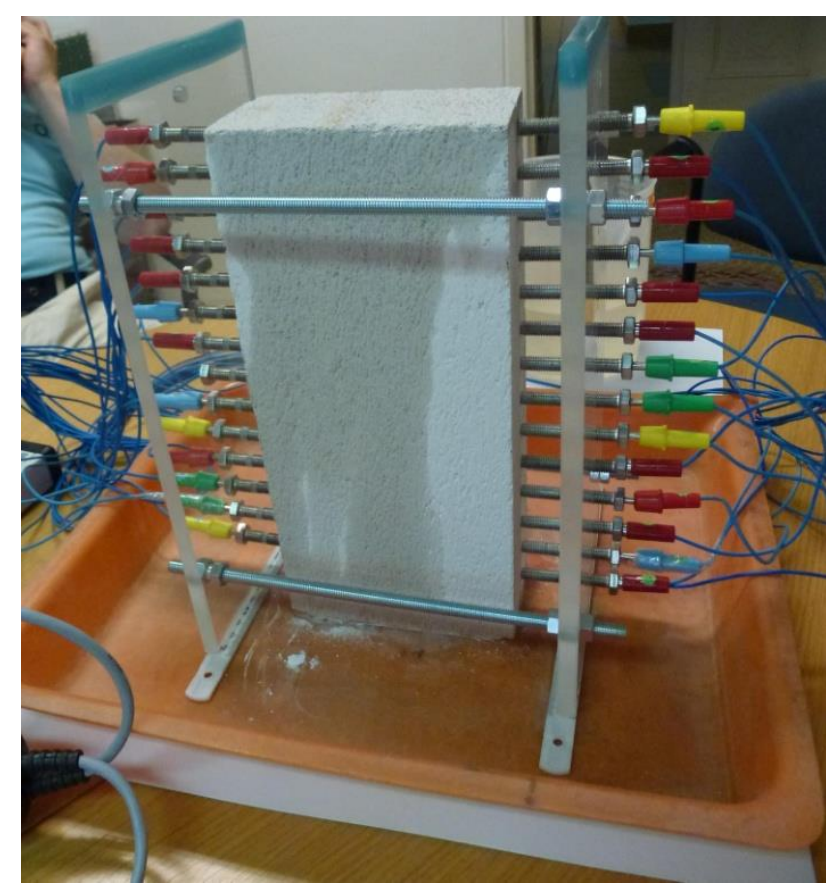

Fig. 5. Experimental aerated concrete block with 14 pairs of sensors for EIS testing.

During the experiment in 40 minutes 11 (one litre) of water was poured on the block. The changes of the humidity distribution in the test sample are shown in Fig. 6.

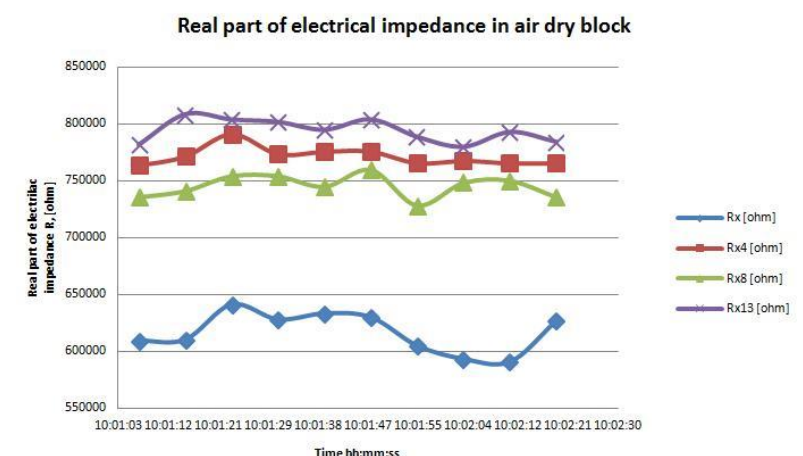

Fig. 6. Partial test results for the air dry aerated concrete block. $\mathrm{Rx} . . . \mathrm{Rx} 13$ - number of probe, as Rx the probe closest to the top of the block and Rx13 closest to the bottom of the block.

In the air dry block it is clearly visible that the top surface (sensor $\mathrm{N}^{\circ} \mathrm{Rx}$ ) has higher humidity rate than other parts of the block. The difference of humidity between the middle parts of the test sample and the top surface is approximately $25 \%$ but in other parts of the test sample the humidity rate is even and changes in the range of $6 \%$.

After the first step of water pouring (approx $170 \mathrm{ml}$ in each step) on the test sample another series of measurements was taken. The distribution of humidity in the same points and one additional point close to the water impact surface is reflected in Fig. 7.

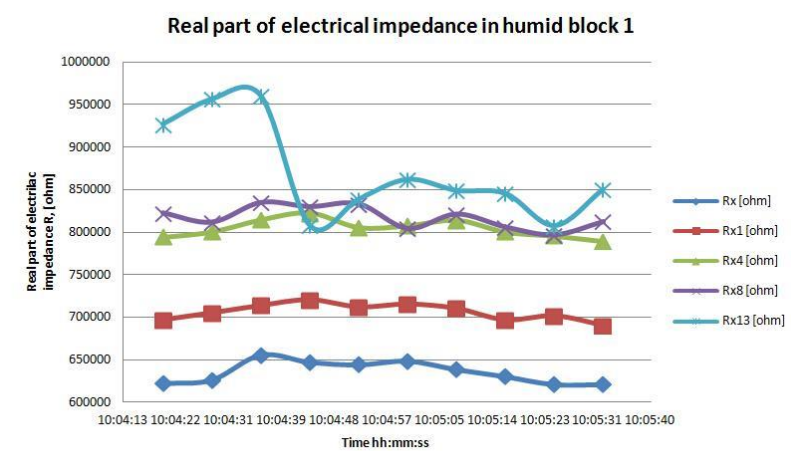

Fig. 7. Partial test results for humid aerated concrete block (step 1 of water impact).

$\mathrm{Rx}$...Rx13 - number of probe, as Rx the probe closest to the top of the block and Rx13 closest to the bottom of the block.

The graph (Fig. 7) confirms the theory of interdependence between the humidity level in aerated concrete block and the value of electric impedance. It shows that close to the surface where water impact was the most intensive, the electric impedance is lower and it rises as the distance from water impact area increases. The results of sensors Rx13 should not be taken into consideration because these sensors were placed at the very bottom of the test sample and due to technical reasons were in the water during the experiment (the water poured on the top of the example later accumulated in the container where the block was placed).

The experiment was continued in 5 additional steps where in each step the same amount of water was poured on the top of the block and respective measurements were taken. The results of the final step are reflected in Fig. 8.

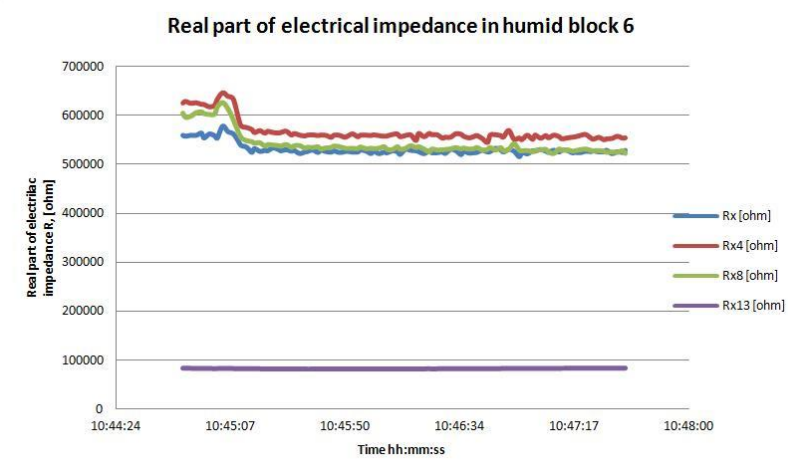

Fig. 8. Partial test results for humid aerated concrete block (step 6 of water impact).

$\mathrm{Rx}$...Rx13 - number of probe, as Rx the probe closest to the top of the block and Rx13 closest to the bottom of the block.

The final stage of the experiment confirms all previous assumptions. It shows that water has infiltrated in deeper layers of the aerated concrete block and the humidity level as well as the electrical impedance value has decreased. The top layer of the block has dried and once more increased the electrical impedance value, but the sensors placed in the lowest part of the example (Rx13) show that the lower part of the block has 6 times higher humidity rate than the middle part of the block. 


\section{Conclusions}

EIS method can be applied for non destructive detection of humidity level throughout aerated concrete constructions. It is easily applicable for testing of relative changes of humidity level in constructions. In such cases no prior calibration of the Z-meter III device is necessary. As there are several types of probes, which can be used as sensors for fully non destructive testing, and the probes, which require prior drilling of holes in the construction in order to make accurate measurements, the method gives the opportunity to apply it for different constructions and situations. The most efficient and convenient type of probes is type 1 (as discussed above). With such probes it is not necessary to access construction from both sides, which is rather difficult for in situ testing.

It is also possible to determine the distribution of absolute humidity rate within a construction with the EIS method. In such case calibration work in laboratory must be done before the in situ testing in order to determine the correlation of the electric impedance value and the absolute humidity rate of the construction. The advantage of EIS method against commonly used method of determination of the material humidity rate by weight differences in dry and saturated conditions is that EIS can show the distribution of the humidity throughout the section of the construction. Other commonly used methods do not allow obtaining such data. The method of determination of absolute humidity rate by EIS in aerated concrete constructions is the subject for further research.

\section{References}

Parilkova, J. et al., 2011. Monitoring of changes in moisture content of the masonry due to microwave radiation using the EIS method. EUREKA 2011, ISBN 978-80-214-4325-9, Brno, 2011.

Parilkova, J. et al., 2005. Optimization of methods for monitoring the unconfined water table and its action in earthfill dams. Sub - report of a project of the Grant Agency of the CR 103/04/0741, LVV UVST FAST VUT v Brne, 2005.

Parilkova, J.; Pavlik, J., 2010. An automated system for analysis of selected characteristics and processes in a porous environment using the EIS method. A partial report of the
Project OE10002 for the year 2010 externally examined, Brno, 2010.

Parilkova, J., 2011. The EIS Method and a Z-meter III Device, a lecture within an event in Litice.

Rupp, D., 2011. Monitoring of seepage conditions of the dam of the Karolinka reservoir. EUREKA 2011

ISBN 978-80-214-4325-9, Brno, 2011.

Kunzel, H. M. et al., 1995. Simultaneus heat and moisture transport in building components. Fraunhofer Institute of Building Physics. Available at:

http://www.aeroc.lv/index.php?page=783\&lang=lat

Hagentoft, C.E., 1999. Building physics fundamentals. Chalmers University of technology, Sweden, Goteburg. Moisture Measurement in Concrete Constructions Exposed to Temperature and Moisture Variations: Nordic Miniseminar of the Nordic Concrete Federation, Espoo, Finland 22.8.1997. ISSN 0357-9387; ISBN 9513845656, 9789513845650.

Brameshuber, W. et al., 2003. Non-destructive Determination of the Water-Content in the Concrete Cover using the Multiring-Electrode, International Symposium (NDT-CE 2003) Non-Destructive Testing in Civil Engineering 2003.

McCarter, W.J.; Garvin, S., 1989. Dependence of Electrical Impedance of Cement-Based Materials on their Moisture Condition. In Journal of Applied Physics Series D: Applied Physics, 22, 11, pp. 1773-1776.

Elsener, B., 1990. Ion Migration and Electric Conductivity in Concrete. Zürich: Schweizerischer Ingenieur- und Architekten-Verein. In Korrosion und Korrosionsschutz. Tl 5. Electrochemical Protection Process for Concrete Building Structures, Symposium 15. November 1990, pp. 51-59.

Guidebook on non-destructive testing of concrete structures. 2002. International atomic energy agency, Vienna, Austria.

Skramlik, J.; Novotny, M., 2008. One-dimensional moisture transport monitored by a non-destructive method. International Journal of Computers, 4 (2).

Sterljagov, A. N., 2007. Sovmestnyj teplo- i vlagoperenos v ograzdajusih konstrukcijah zdanij iz gazobetona: avtoref. dis. kand. tehn. nauk. Novosibirsk. 2007.

Tamm, Ju.; Jygioja, E., 2006. Itogovyj otcet. Opredelenie teplotehniceskih svojstv i vlažnostnogo rezima sten iz blokov AEROC EcoTerm. - Tallin, 2006. - 34 s. 